\title{
Poly(ethylene glycol)-Mediated Assembly of Vaccine Particles to Improve Stability and Immunogenicity
}

Guiqiang Zhang,,${ }^{\dagger}$ Xiao Fu,${ }^{\dagger}$ Haifeng Sun,${ }^{\dagger}$ Peiyu Zhang, ${ }^{\dagger}$ Shumei Zhai,${ }^{\dagger}$ Jingcheng Hao,${ }^{\dagger}$ Ming Hu, ${ }^{\mathbb{T}, *}$ Jiwei Cui ${ }^{\dagger, \ddagger}, \S, *$

tKey Laboratory of Colloid and Interface Chemistry of the Ministry of Education, School of Chemistry and Chemical Engineering, Shandong University, Jinan, Shandong 250100, China.

\$State Key Laboratory of Microbial Technology, Shandong University, Qingdao, Shandong 266237, China.

§Advanced Medical Research Institute, Shandong University, Jinan, Shandong 250012, China.

ISchool of Physics and Electronic Science, East China Normal University, Shanghai 200241, China.

E-mail: jwcui@sdu.edu.cn; mhu@phy.ecnu.edu.cn 
Table S1. Particle size, PDI and zeta potential of NPs (mean \pm SD, $n=3$ ).

\begin{tabular}{cccc}
\hline Group & Size $(\mathrm{nm})$ & PDI & Zeta $(\mathrm{mV})$ \\
\hline ZIF-8 & $220 \pm 1.8$ & 0.183 & $25.3 \pm 1.3$ \\
OVA@ZIF-8 & $492 \pm 5.2$ & 0.142 & $-16.2 \pm 0.4$ \\
OVA-CpG@ZIF-8 & $537 \pm 8.3$ & 0.061 & $-17.5 \pm 0.5$ \\
\hline
\end{tabular}



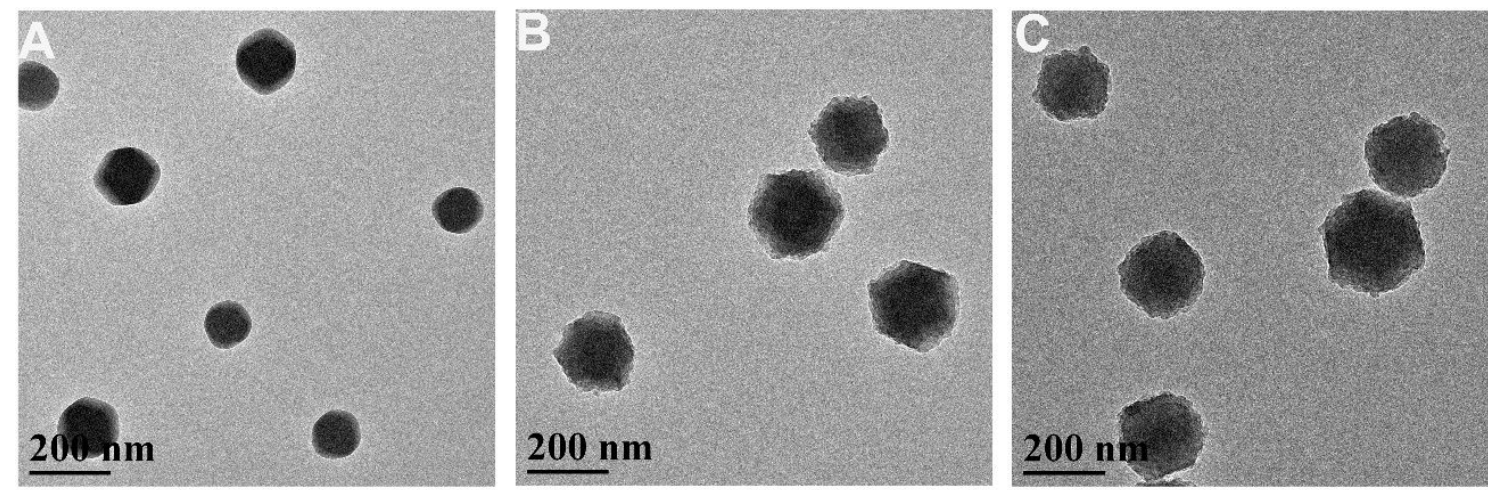

Figure S1. TEM images of ZIF-8 (A), OVA@ZIF-8 (B), and OVA-CpG@ZIF-8 (C) NPs. 
A

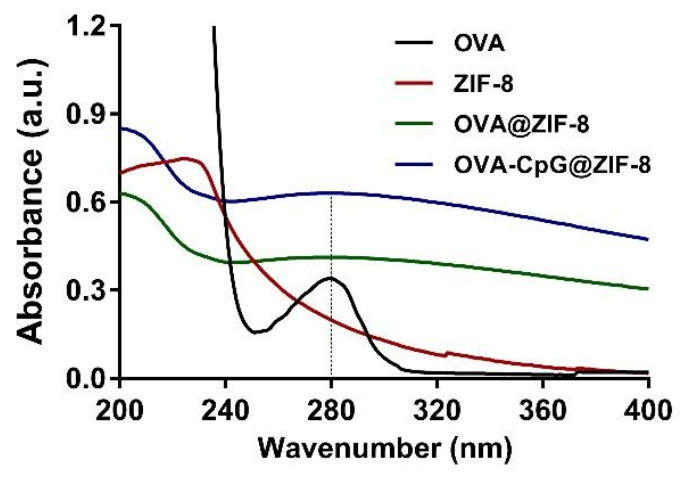

B

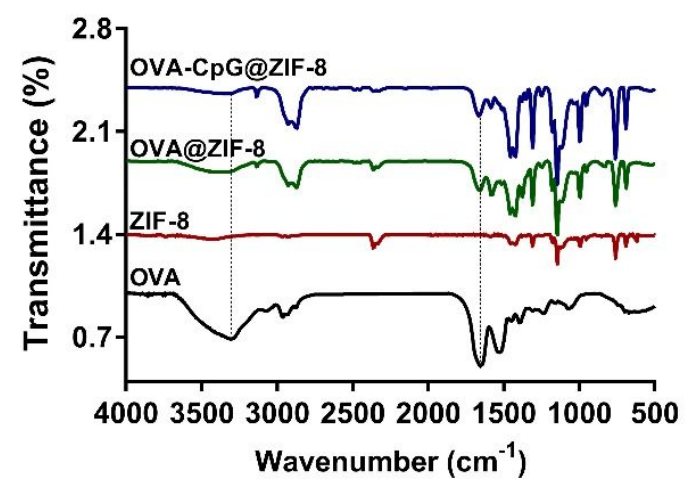

Figure S2. (A) UV-Vis and (B) FTIR spectra of free OVA, ZIF-8, OVA@ZIF-8, and OVACpG@ZIF-8 NPs. 


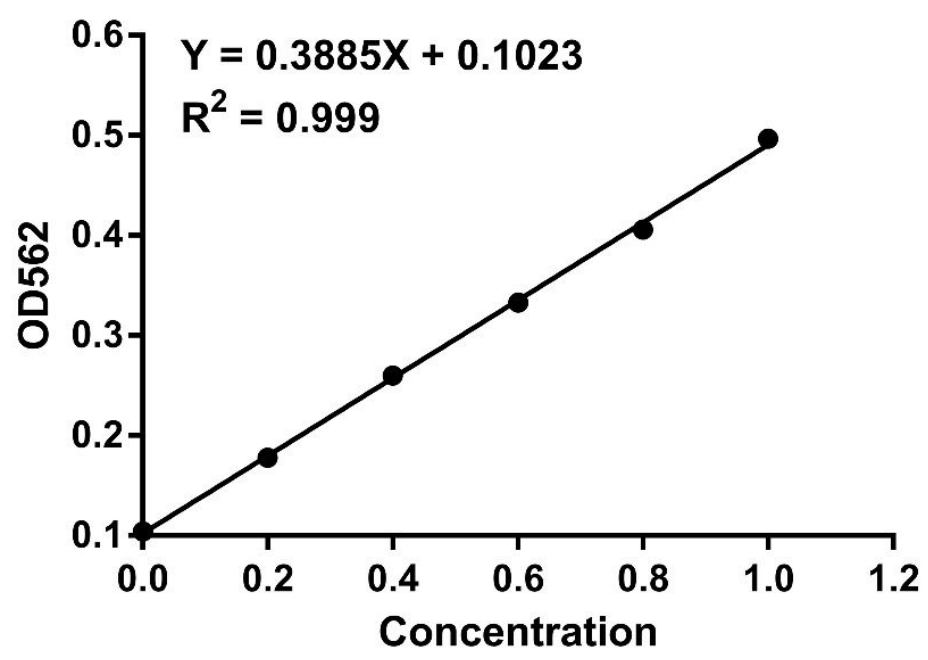

Figure S3. Calibration curve of OVA used for quantifying the amount of OVA in the solution. 


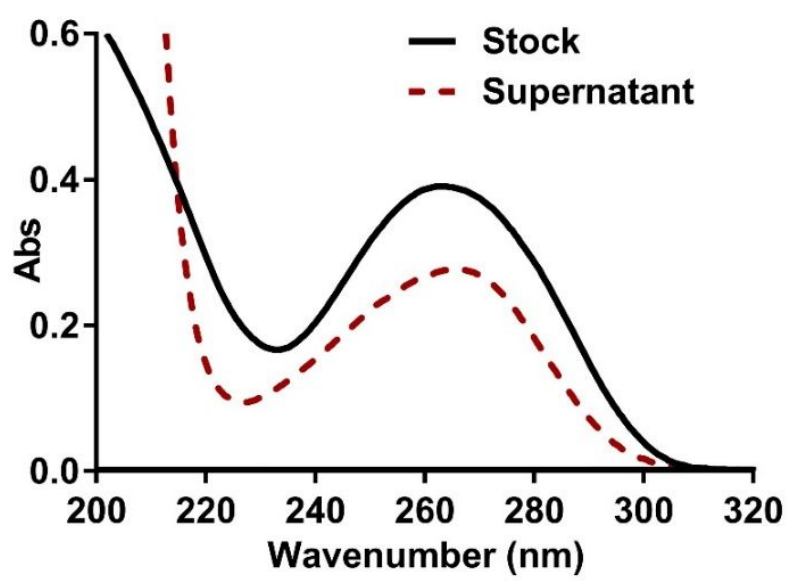

Figure S4. Quantification of CpG loaded in the OVA-CpG@ZIF-8 NPs. The spectra of the stock solution of $\mathrm{CpG}$ and the supernatant of $\mathrm{CpG}$ after encapsulation. 

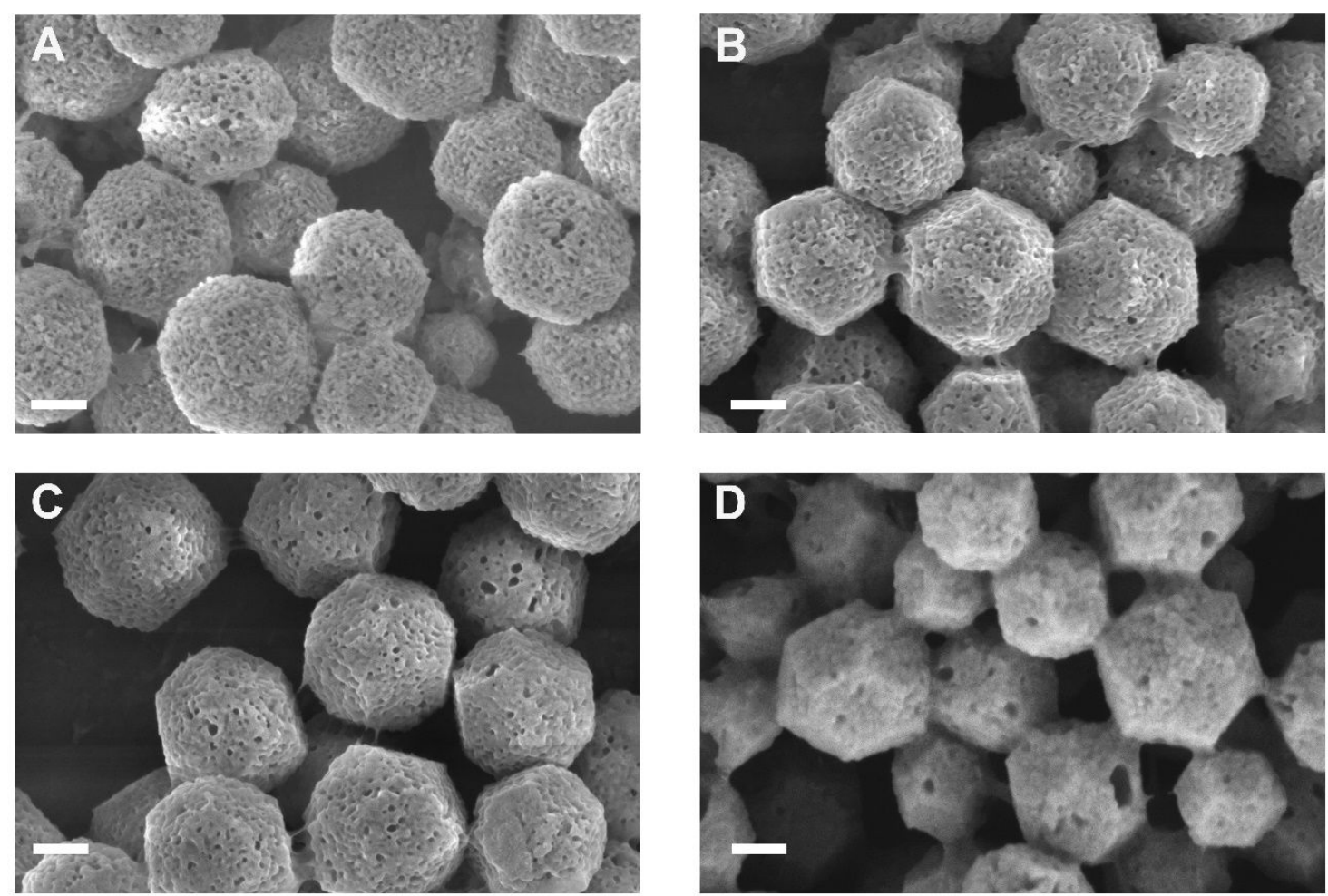

Figure S5. SEM images of OVA-CpG@ZIF-8 NPs after storage in water for 7 (A), 14

(B), 21 (C), 30 (D) days. Scale bars are $200 \mathrm{~nm}$. 


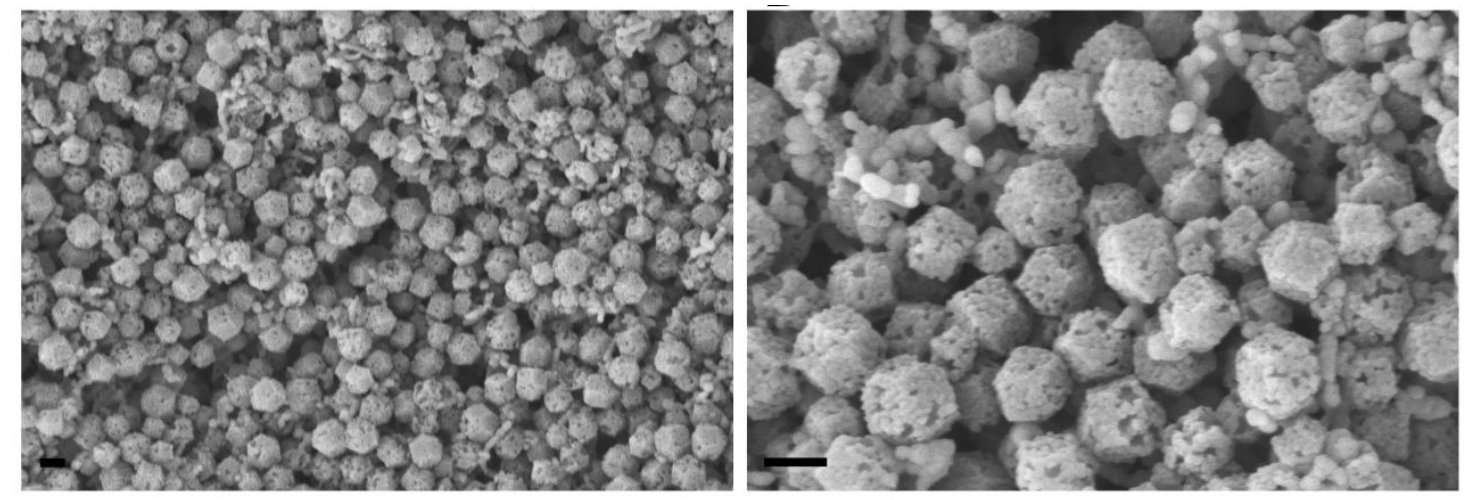

Figure S6. SEM images of OVA-CpG@ZIF-8 NPs after storage in PBS $(\mathrm{pH}=7.4)$ for 24

h. Scale bars are $200 \mathrm{~nm}$. 
A
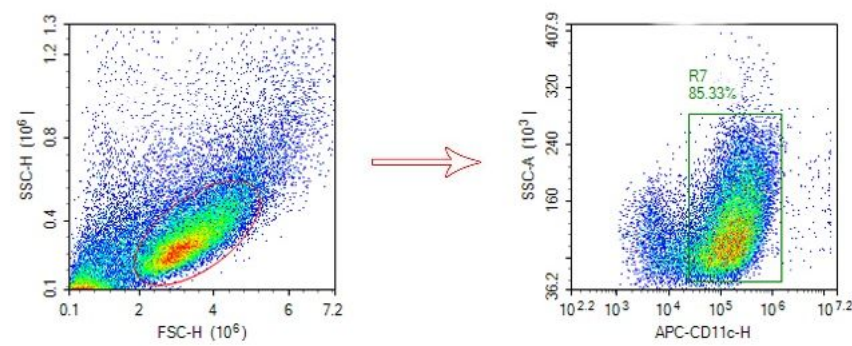

B

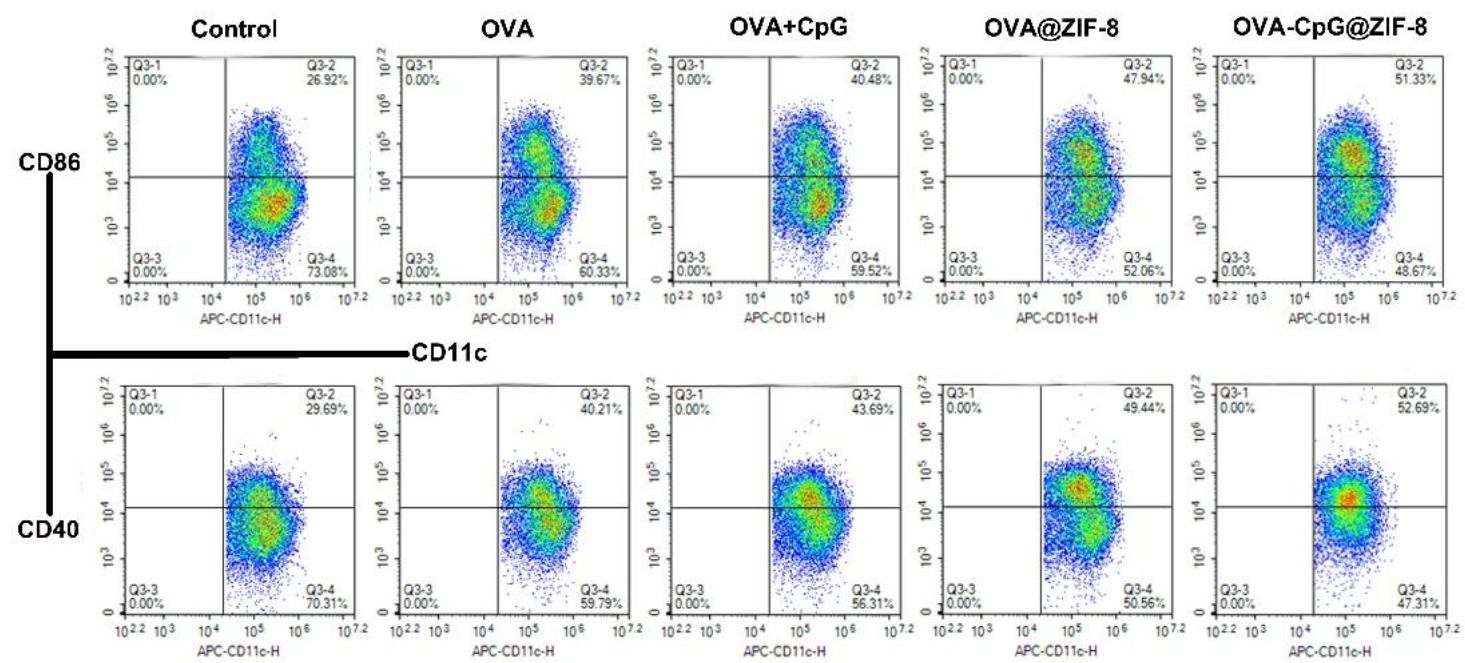

Figure S7. (A) Gating strategy for BMDCs maturation. Living cells were identified based on FSC-H versus SSC-H profiles. BMDCs were identified as CD11 $\mathrm{C}^{+}$. (B) Representative graphs of the expression of CD40 and CD86 on BMDCs after incubation with OVA, OVA+CpG, OVA@ZIF-8 and OVA-CpG@ZIF-8 NPs, respectively. 


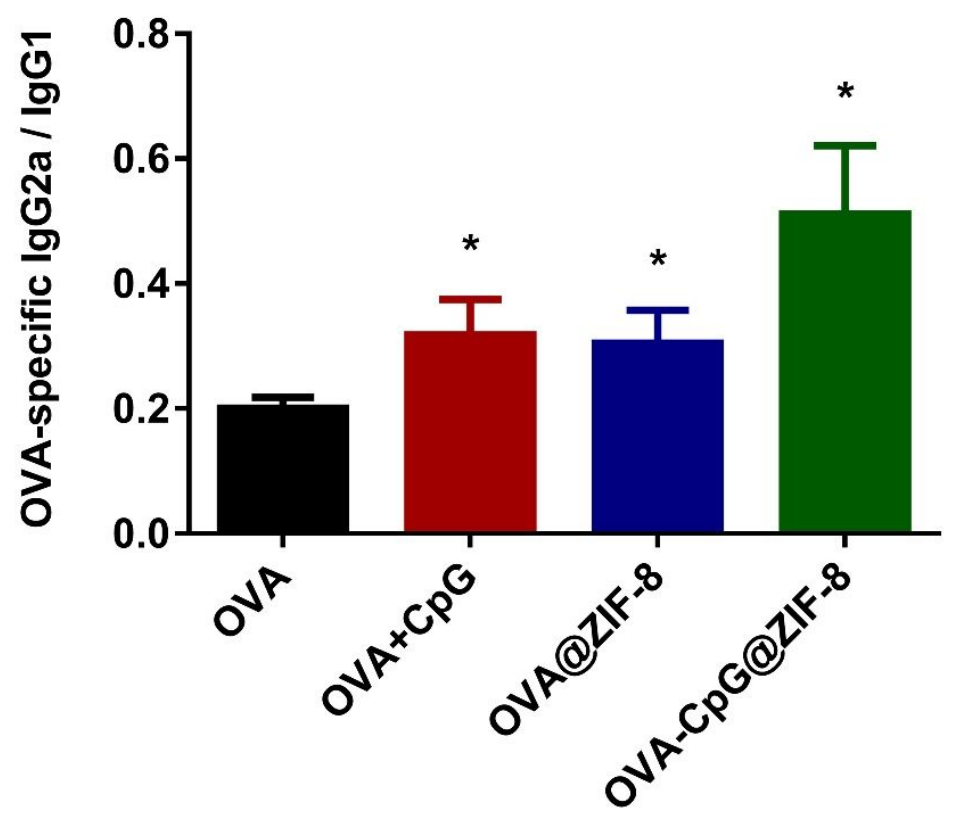

Figure S8. Effect of samples on anti-OVA IgG2a and anti-PCV2 IgG1 ratio (IgG2a/lgG1) in immunized mice at day 35 after the first immunization. Data are represented as the mean $\pm \mathrm{SD}(\mathrm{n}=6) .{ }^{*} P<0.05$ compared to the OVA group. 

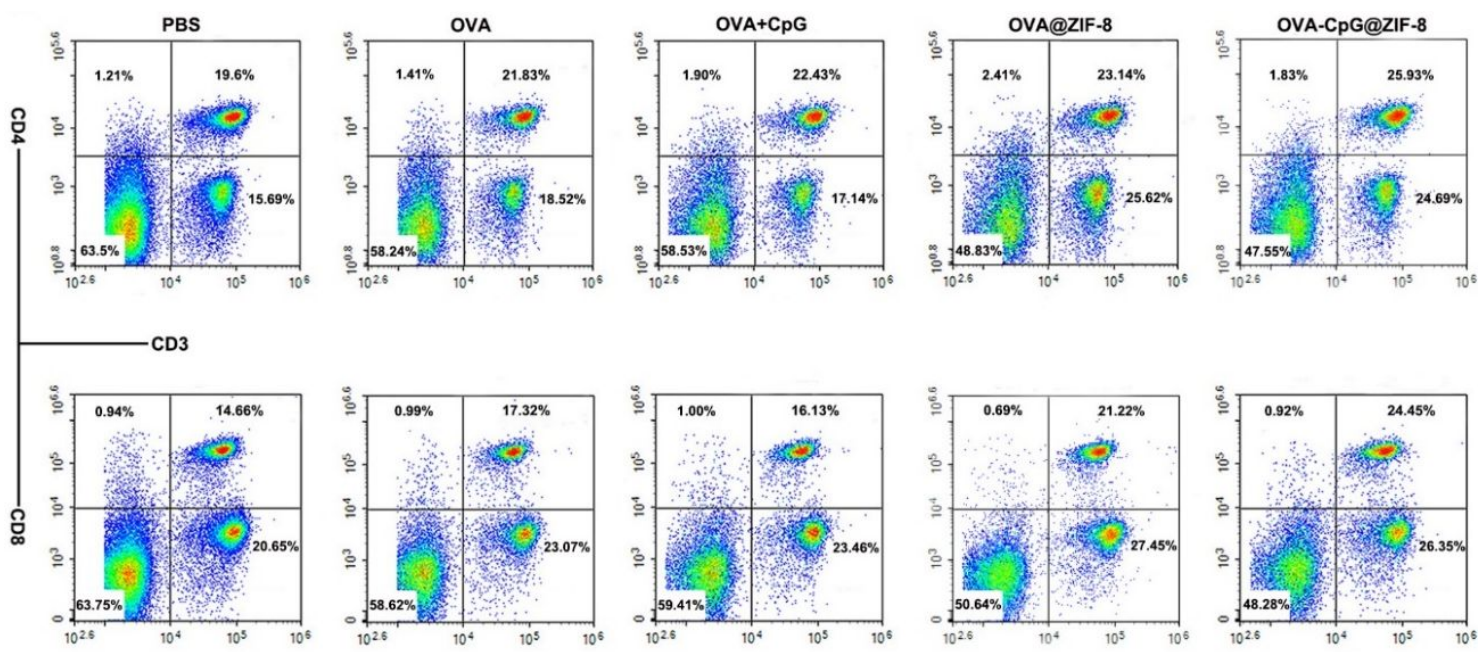

Figure S9. Flow cytometry graphs showing the $\mathrm{CD} 3^{+} \mathrm{CD} 4^{+}$and $\mathrm{CD} 3^{+} \mathrm{CD} 8^{+} \mathrm{T}$ cells in spleen harvested from immunized mice. 

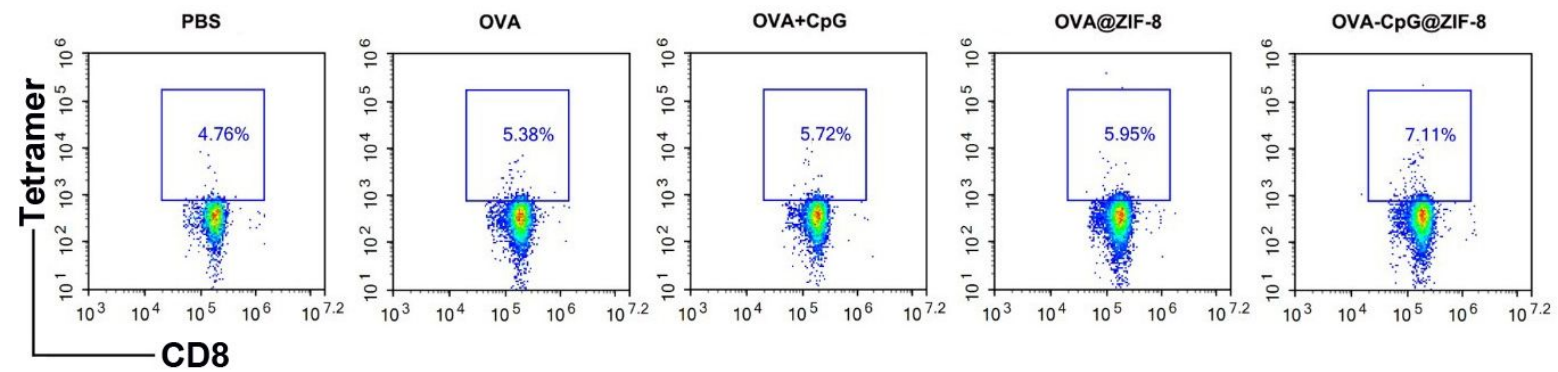

Figure S10. Antigen-specific CD8+ T cells in spleen. 


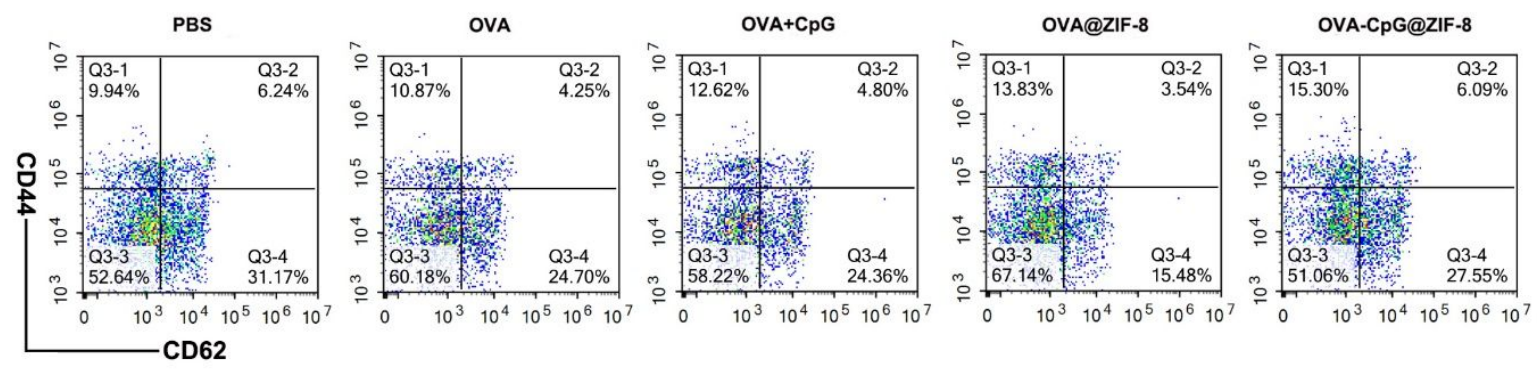

Figure S11. Representative graphs of effector memory T cells (CD44+ $\left.{ }^{+} \mathrm{CD} 62 \mathrm{~L}^{-}\right)$in $\mathrm{CD} 8^{+}$ T cells. 


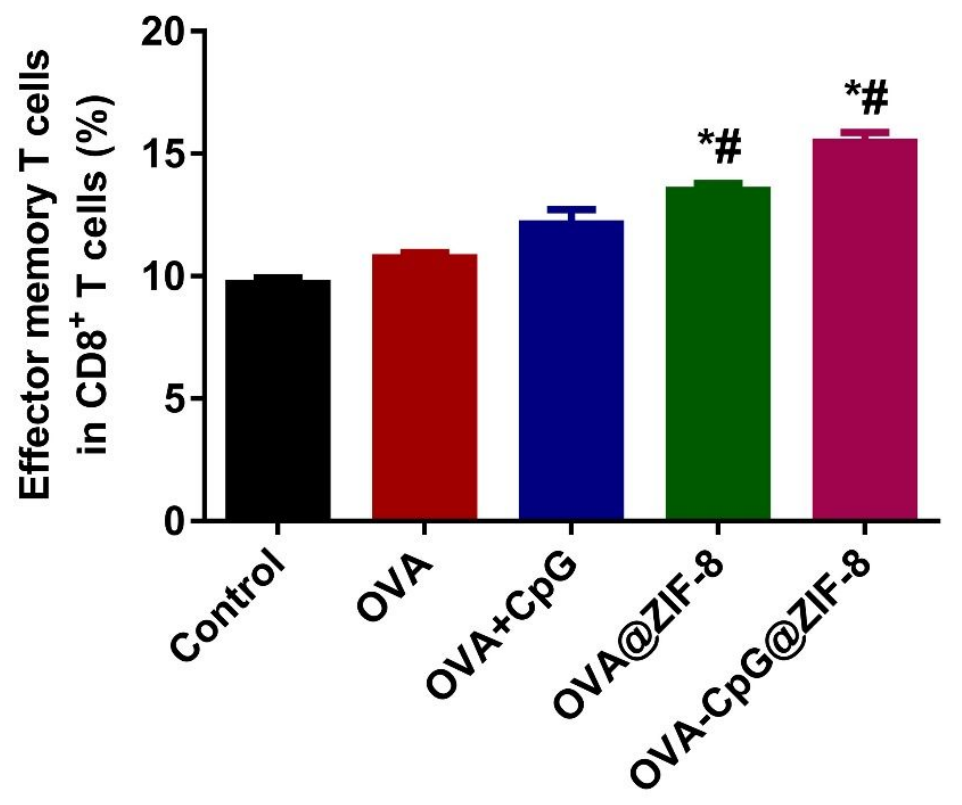

Figure $\mathrm{S12}$. The frequency of effector memory $\mathrm{T}$ cells $\left(\mathrm{CD} 44^{+} \mathrm{CD} 62 \mathrm{~L}^{-}\right)$in $\mathrm{CD} 8^{+} \mathrm{T}$ cells. Data are represented as the means $\pm S D(n=6) .{ }^{*} P<0.05$, compared to the OVA group. $\# P<0.05$, compared to the OVA+CpG group. 


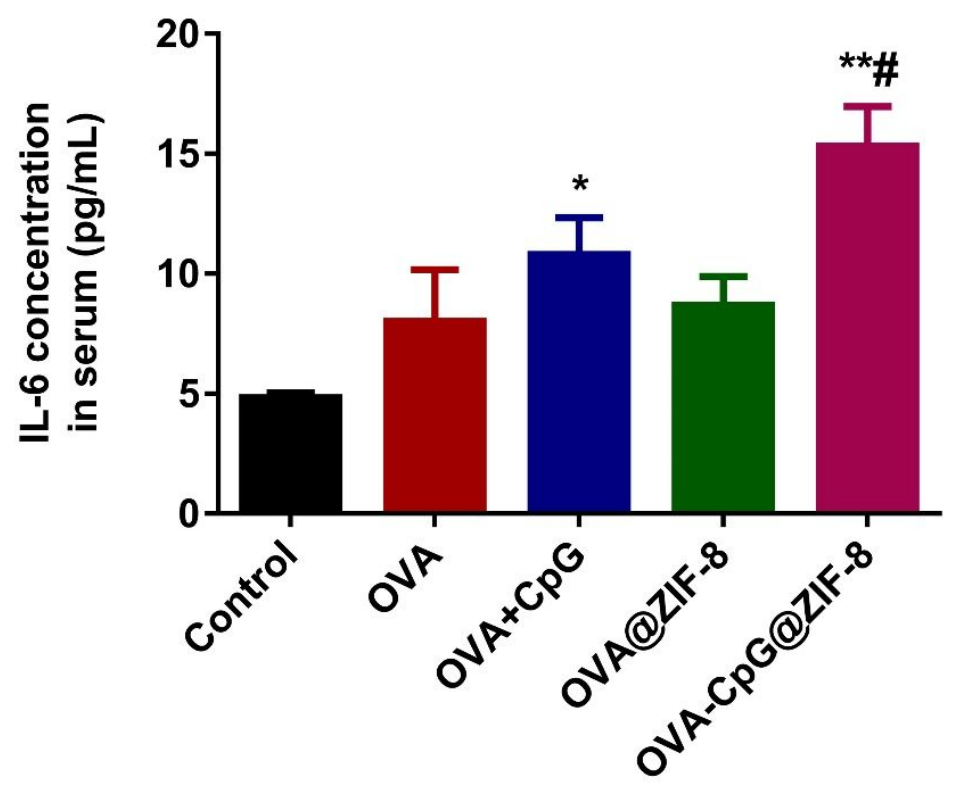

Figure S13. Production of IL-6 in serum from immunized mice. Data are represented as the means $\pm \mathrm{SD}(\mathrm{n}=6) .{ }^{*} P<0.05$ or ${ }^{* *} P<0.01$, compared to the OVA group. ${ }^{\#} P<$ 0.05 , compared to the OVA+CpG group. 

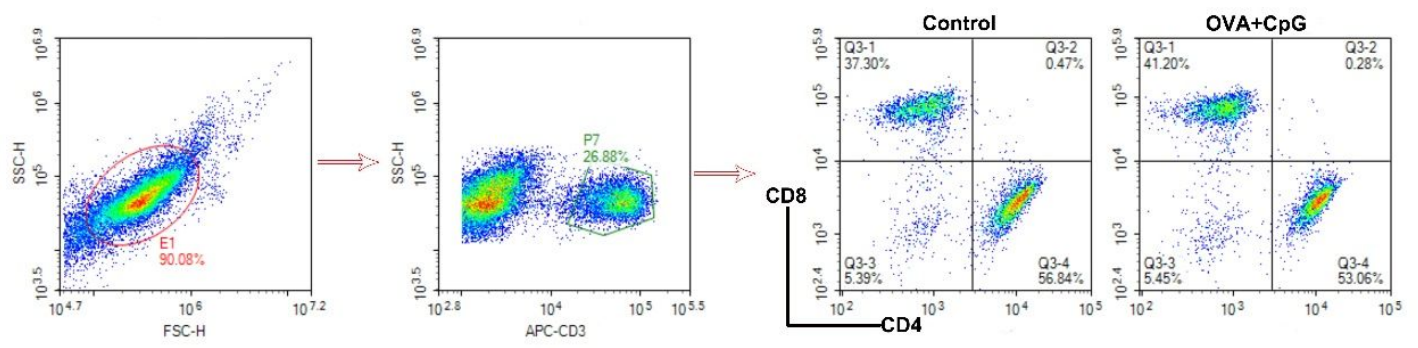

Figure S14. Gating strategy for $\mathrm{CD}^{+} \mathrm{CD} 4^{+}$and $\mathrm{CD} 3^{+} \mathrm{CD} 8^{+} \mathrm{T}$ cells in spleen. Living cells were identified based on FSC-H versus SSC-H profiles. T cells were identified as CD3 cells, whereas $\mathrm{CD} 4 \mathrm{~T}$ cells and $\mathrm{CD} 8 \mathrm{~T}$ cells were $\mathrm{CD} 3^{+} \mathrm{CD} 4^{+}$and $\mathrm{CD} 3^{+} \mathrm{CD} 8^{+}$. 
A

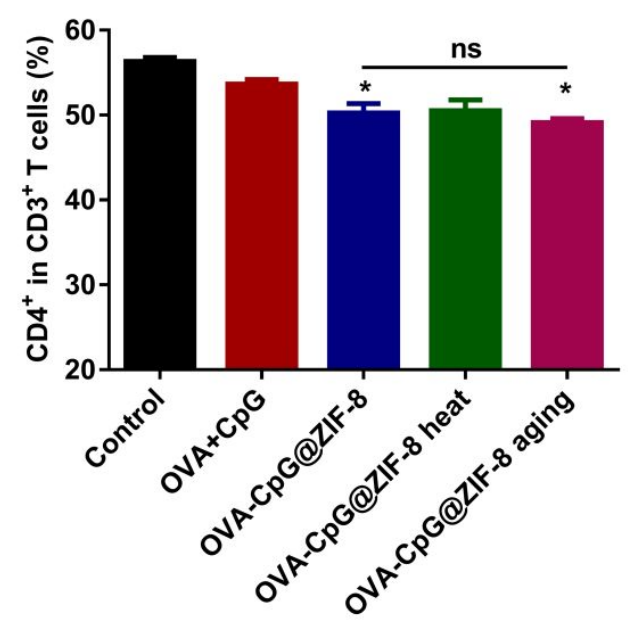

B

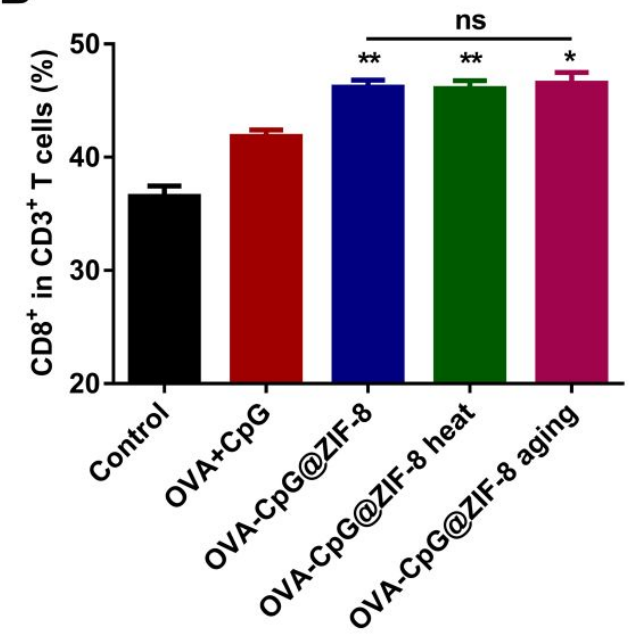

Figure S15. (A) $\mathrm{CD}^{+} \mathrm{CD}^{+}$, (B) $\mathrm{CD}^{+}{ }^{+} \mathrm{CD} 8^{+}$cells in in spleen harvested from immunized mice.

Data are represented as the mean $\pm \mathrm{SD}(\mathrm{n}=6) .{ }^{*} P<0.05$ or ${ }^{* *} P<0.01$, compared to the OVA+CpG group. 

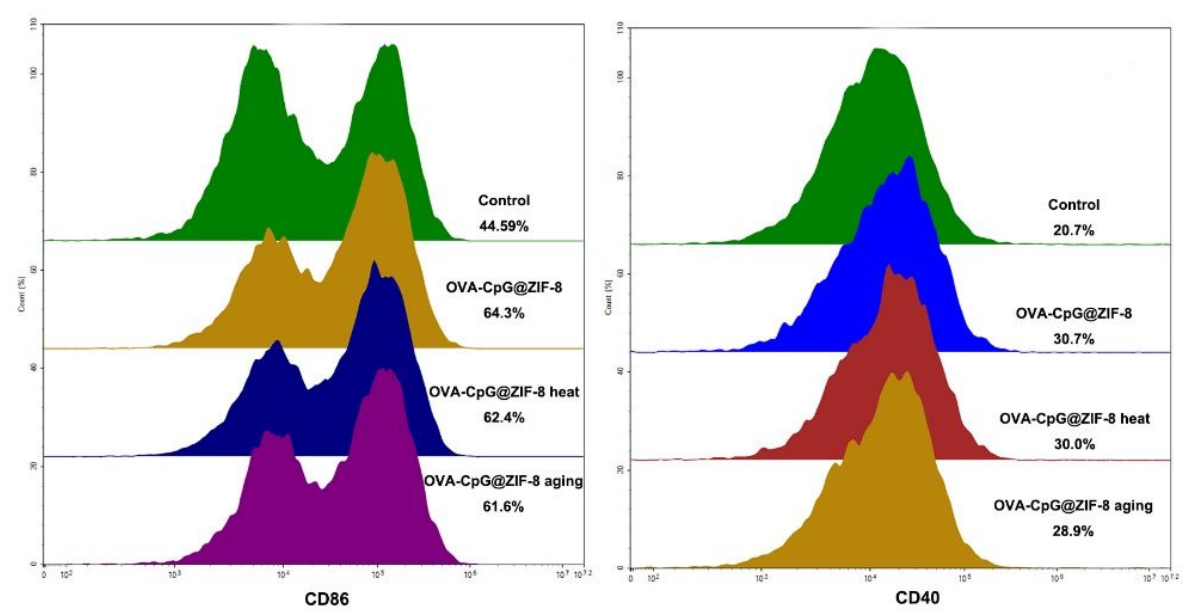

Figure S16. Representative graphs of the expression of CD40 and CD86 on BMDCs. 